\title{
Somatic mutational spectrum analysis in a prospective series of 104 gastrointestinal stromal tumors
}

\author{
DAVID GUENAT $^{1-4^{*}}$, OLIVIER DEROO $^{1,2^{*}}$, SANDRINE MAGNIN $^{1,2,4,5}$, LOÏC CHAIGNEAU $^{1}$, FRANCK MONNIEN $^{1}$, \\ CHRISTOPHE BORG ${ }^{1-4}$, CHRISTIANE MOUGIN ${ }^{1,2,4,5}$, JEAN-FRANÇOIS EMILE ${ }^{6,7}$ and JEAN-LUC PRÉTET ${ }^{1,2,4,5}$ \\ ${ }^{1}$ CHRU Besançon; ${ }^{2}$ Univ. Bourgogne Franche-Comté; ${ }^{3}$ INSERM U1098, Besançon; ${ }^{4}$ LabEx LipSTIC, Besançon/Dijon; \\ ${ }^{5}$ EA 3181, Besançon; ${ }^{6}$ Université Versailles; ${ }^{7}$ AP-HP, Hôpital Ambroise Pare, Boulogne, France
}

Received June 22, 2016; Accepted August 23, 2016

DOI: $10.3892 / o r .2017 .5384$

\begin{abstract}
Gastrointestinal stromal tumors (GISTs) are mesenchymal tumors distinguished by driver mutations in proto-oncogenes KIT or PDGFRA in $85-90 \%$ of cases. These mutations have been linked to the response to imatinib, a multikinase inhibitor, and have independent prognostic impact. Here, we describe the prospective study of the molecular characteristics of 104 GISTs from French adult patients analyzed routinely through the National Hospital Program of Molecular Cancer Diagnosis. All patients with GISTs diagnosed at the University Hospital of Besançon between August 2005 and October 2014 were prospectively included in the present study. KIT, PDGFRA and KRAS-codons 12 and 13 as well as BRAF codon 600 mutations were analyzed by Sanger sequencing or SNaPshot. KIT and PDGFRA mutations were detected in 71.2 and $19.2 \%$ of the cases, respectively. A total of 43 different mutations were detected of which 13 had never been described. As expected, KIT exon 9 and PDGFRA exon 18 mutations were associated with small bowel and gastric localizations respectively. No mutation was found in $K R A S$ and $B R A F$. Molecular studies are critical to improve the management of GISTs. Our study enhances the current knowledge by describing 13 new
\end{abstract}

Correspondence to: Dr David Guenat, Centre Hospitalier Régional Universitaire Besançon, Laboratoire de Biologie Cellulaire et Moléculaire, PC BIO +2 (Room H1.2), 1 Boulevard Fleming, 25000 Besançon, France

E-mail: david.guenat@univ-fcomte.fr

${ }^{*}$ Contributed equally

Abbreviations: AFIP, Armed Forces Institute of Pathology; COSMIC, Catalogue of Somatic Mutations in Cancer; EGFR, epidermal growth factor receptor; FFPE, formalin-fixed paraffinembedded; GISTs, gastrointestinal stromal tumors; KRAS, Kirsten rat sarcoma; MLH1, mutL homolog 1; DNA, deoxyribonucleic acid; NIH, National Institutes of Health; PDGFRA, platelet-derived growth factor receptor $\alpha$; SDHB, succinate dehydrogenase complex, subunit B; SNP, single-nucleotide polymorphism

Key words: gastrointestinal stromal tumors, GIST, mutation, KIT, PDGFRA, KRAS, BRAF, France mutations in KIT. A common molecular pattern in all KIT exon 11 substitutions is also described for the first time in this study but its significance remains unknown since genetic and environmental risk factors favoring the development of GISTs such as DNA repair defects and exposure to carcinogens are not currently known.

\section{Introduction}

Gastrointestinal stromal tumors (GISTs) are the most common mesenchymal tumors and account for $18 \%$ of all sarcomas (1).

GISTs develop from a small subset of interstitial cells named Cajal cells and may arise anywhere in the gastrointestinal tract (60-70\% in the stomach and $20-30 \%$ in the small intestine) and more rarely (less than 5\%) in the omentum or mesentery (2). GISTs usually occur in adults with a median age of 55-60 years. The annual incidence of GISTs worldwide is estimated to be between 11 and 19.6 per million inhabitants, corresponding to 500-600 new cases per year in France $(3,4)$.

During the past decade, GISTs have emerged as a distinct group of gastrointestinal tumors with the discovery of the oncogenic role of the tyrosine kinase receptor KIT (also called stem cell factor receptor) whose expression is observed by immunohistochemical staining in more than 90\% of GISTs (5). In 75\% of GISTs expressing the protooncogene KIT, a gain-of-function mutation in the tyrosine kinase domain of KIT leads to its constitutive activation (6). Alternatively, somatic mutations in platelet-derived growth factor receptor $\alpha$ (PDGFRA), another tyrosine kinase receptor encoding gene can drive the development of GISTs in $15 \%$ of cases $(7,8)$. In approximately $85 \%$ of pediatric GISTs and in a small subset of adult GISTs (10-15\%), KIT and PDGFRA mutations have not been identified (9). Mutations of $B R A F$ have been reported in $3.5-13 \%$ of KIT/PDGFRA wild-type tumors but the pathogenic significance of such mutations still remains unknown (10-12).

The vast majority of GISTs are sporadic but genetic predispositions have also been described. Thus, $7 \%$ of patients with neurofibromatosis type I develop GISTs, mostly multiple GISTs without KIT mutations. More rarely, germline mutations in succinate dehydrogenase complex, subunit B $(S D H B)$, KIT or PDGFRA have been observed in familial forms of GIST (13-16). 
The prognosis of GISTs varies widely. Since GISTs generally evolve without symptoms, more than $10 \%$ are diagnosed at the metastatic state. Complete surgical resection is the current standard of care in most localized GISTs. After resection, the estimated 15-year recurrence-free survival is $59.9 \%$. Older age, a tumor size larger than $10 \mathrm{~cm}$, a high mitotic count, non-gastric localization, presence of tumor rupture and male gender are independent adverse prognostic factors $(17,18)$. For localized GISTs, the risk of relapse can be evaluated using Armed Forces Institute of Pathology (AFIP) or National Institutes of Health (NIH) classifications that are based on localization, tumor size, mitotic index and presence of rupture of the primary tumor $(19,20)$. These classifications are critical for the management of adjuvant treatment in patients with GISTs and are likely to be enhanced by incorporating the mutational status of GISTs (21).

Indeed, the rapid evolution in understanding the oncogenesis of GISTs leads to the use of effective targeted therapies. Most GISTs with KIT or PDGFRA mutations respond to imatinib, a multikinase inhibitor (22-25). Better responses are observed in GISTs with $K I T$ exon 11 mutations than in patients with KIT exon 9 mutations, PDGFRA mutations or without mutations (26). Unfortunately, around half of the patients who initially respond to imatinib develop resistance after a long period of treatment. Resistance to imatinib has been linked to secondary mutations involving mostly the same gene as the primary driver mutation (27-32). Alternative tyrosine kinase inhibitors that target KIT and PDGFRA such as sunitinib, nilotinib, sorafenib, regorafenib as well as other investigational inhibitors are currently being evaluated to treat imatinib-resistant GISTs (33-36).

The KIT and PDGFRA mutational spectrums have been well characterized in population-based studies in France (4), Norway (37) and Switzerland (38). These studies have shown that $50-60 \%$ of primary GISTs present mutations in KIT exon 11 (encoding the transmembrane domain), 5-10\% in KIT exon 9 (extracellular domain), 1-3\% in KIT exon 13 (tyrosine kinase domain 1), <1\% in KIT exon 17 (tyrosine kinase domain 2), 2-5\% in PDGFRA exon 12 (transmembrane domain) and 2-12\% in PDGFRA exon 18 (tyrosine kinase domain 2). Mutations in $K I T$ exon 11 are the most heterogeneous mutations observed in GISTs with about 50\% deletions, 34\% substitutions, $6 \%$ duplications/insertions and $11 \%$ complex mutations.

We provide here a prospective study of the molecular characteristics of a series of 104 GISTs in hospital-based French adult patients.

\section{Materials and methods}

Study design and patients. All GIST cases diagnosed between August 2005 and October 2014 in the University Hospital of Besançon, France $(n=104)$ were prospectively identified through the Department of Pathology and the Regional Molecular Genetics Centre of Besançon.

All patients with GIST during this period had routinely benefited from a molecular diagnosis according to the French National Public Cancer Program managed by the National Institute of Cancer (Institut National du Cancer, INCa) (39). All specimens used in the present study were primary tumors except for 4 specimens corresponding to metastasis.
Ethics statement. All procedures followed were in accordance with the ethical standards of the committee responsible for human experimentation (institutional and national) and with the Helsinki Declaration of 1964 and later versions. According to the French legislation (Public Health Code modified by the law no. 2004-806, August 9, 2004 and the Huriet-Serusclat act 88-1138, December 20, 1988) and as this study only involved data extracted from medical records and stored histological specimens, no informed consent from the patients was necessary. Data collected from the Department of Pathology were strictly anonymous. The collection of specimens and their use for research were approved by the Ethics Committee of the University Hospital of Besançon.

Histopathological evaluation. The diagnosis of GIST was based on histological examination and confirmed using KIT/CD117 (clone 104D2, dilution 1/300; Dako, Les Ulis, France) and DOG-1 (clone SP31, dilution 1/150; Thermo Fisher Scientific, Villebon-sur-Yvette, France) immunostaining when appropriate. In each case, the largest diameter of the tumor was measured. Mitotic index was evaluated on $12.5 \mathrm{~mm}^{2}$ of tumor and then converted to the number of mitoses $/ 5 \mathrm{~mm}^{2}$. For localized GISTs, the potential risk of relapse was evaluated according to Miettinen criteria (20).

DNA extraction. Tumor genomic DNA was extracted from formalin-fixed and paraffin-embedded (FFPE) or frozen tissues using QIAmp DNA Mini kit (Qiagen, Courtabeuf, France) according to the manufacturer's instructions. Prior to DNA extraction, separate hematoxylin and eosin stained slides were reviewed by a pathologist and manually microdissected when appropriate to ensure tumor content greater than $20 \%$. Depending on the size of the fixed tissue, between 3 and 8 FFPE tissue sections of $10 \mu \mathrm{m}$ thickness were processed for DNA extraction. DNA and tissue samples were collected by the Biobank BB-0033-00024 'Tumorothèque Régionale de Franche-Comté (TRFC)'.

KIT and PDGFRA mutations analysis by direct sequencing. A sequential strategy analysis was adopted for the screening of KIT and PDGFRA mutations by Sanger sequencing. The most frequent sites of mutations (exons 9 and 11 of $K I T$ and exon 18 of PDGFRA) were first analyzed. When no mutation was detected in the former exons, exons 13 and 17 of KIT and exon 12 of PDGFRA were subsequently sequenced. Genomic sequences of KIT (ENST00000288135) and PDGFRA (ENST00000257290) were obtained from Ensembl database (www.ensembl.org). Specific primers were designed using the online Primer-BLAST software (www.ncbi.nlm.nih. gov/tools/primer-blast/) (40). Table I shows the details of the primer sequences and their annealing temperatures. Targeted sequences were amplified by PCR using the Qiagen Multiplex PCR kit (Qiagen). PCR conditions were as follows: $94^{\circ} \mathrm{C}$ for $15 \mathrm{~min}, 40$ cycles of $92^{\circ} \mathrm{C}$ for $1 \mathrm{~min}$, specific annealing temperature for $30 \mathrm{sec}, 72^{\circ} \mathrm{C}$ for $45 \mathrm{sec}$ and finally $7 \mathrm{~min}$ at $72^{\circ} \mathrm{C}$. PCR products were purified using the gel extraction kit NucleoSpin Gel and PCR Clean-up (Macherey-Nagel, Hoerdt, France). Bidirectional sequencing reaction was performed using the DTCS Quick Start kit (SCIEX, Les Ulis, France). Reactions were run according to the following protocol: one cycle at $96^{\circ} \mathrm{C}$ 
Table I. PCR primers used for sequencing of KIT and PDGFRA.

\begin{tabular}{|c|c|c|c|}
\hline Gene/exon & Primer sequences $\left(5^{\prime} \rightarrow 3^{\prime}\right)$ & $\begin{array}{c}\text { Annealing } \\
\text { temperature }\left({ }^{\circ} \mathrm{C}\right)\end{array}$ & $\begin{array}{l}\text { Product } \\
\text { size (bp) }\end{array}$ \\
\hline KIT 9 & $\begin{array}{l}\text { F: ATGCTCTGCTTCTGTACTG } \\
\text { R: GCCTAAACATCCCCTTAAATTGG }\end{array}$ & 56 & 234 \\
\hline KIT 11 & $\begin{array}{l}\text { F: CTCTCCAGAGTGCTCTAATGAC } \\
\text { R: AGCCCCTGTTTCATACTGACC }\end{array}$ & 56 & 219 \\
\hline KIT 13 & $\begin{array}{l}\text { F: GCTTGACATCAGTTTGCCAG } \\
\text { R: GAGAACAACAGTCTGGGTAA }\end{array}$ & 56 & 294 \\
\hline KIT 17 & $\begin{array}{l}\text { F: TCTCCTCCAACCTAATAGTGTAT } \\
\text { R: GCAGGACTGTCAAGCAGAGAAT }\end{array}$ & 56 & 173 \\
\hline PDGFRA 12 & $\begin{array}{l}\text { F: AAGCTCTGGTGCACTGGGACTT } \\
\text { R: ATTGTAAAGTTGTGTGCAAGGGA }\end{array}$ & 65 & 251 \\
\hline PDGFRA 18 & $\begin{array}{l}\text { F: TACAGATGGCTTGATCCTGAGT } \\
\text { R: AGTGTGGGAGGATGAGCCTG }\end{array}$ & 60 & 212 \\
\hline
\end{tabular}

PDGFRA, platelet-derived growth factor receptor $\alpha$; , forward; $\mathrm{R}$, reverse.

for $1 \mathrm{~min} ; 15$ cycles at $96^{\circ} \mathrm{C}$ for $10 \mathrm{sec}, 50^{\circ} \mathrm{C}$ for $5 \mathrm{sec}, 60^{\circ} \mathrm{C}$ for $1 \mathrm{~min} 15 \mathrm{sec} ; 5$ cycles of $96^{\circ} \mathrm{C}$ for $10 \mathrm{sec}, 50^{\circ} \mathrm{C}$ for $5 \mathrm{sec}$, $60^{\circ} \mathrm{C}$ for $1 \mathrm{~min} 30 \mathrm{sec} ; 5 \mathrm{cycles}$ of $96^{\circ} \mathrm{C}$ for $10 \mathrm{sec}, 50^{\circ} \mathrm{C}$ for $5 \mathrm{sec}$ and $60^{\circ} \mathrm{C}$ for $2 \mathrm{~min}$. After purification with a NucleoSEQ kit (Macherey-Nagel), samples were run and analyzed on a CEQ 8000 sequencer (SCIEX). Finally, the sequences obtained were compared with the reference sequence of KIT or PDGFRA using CEQ 8000 analysis software. Our procedure included a systematic double review by two independent biologists.

KRAS and BRAF mutational analysis. Furthermore, all $K I T / P D G F R A$ wild-type samples $(\mathrm{n}=10)$ were tested for Kirsten rat sarcoma $(K R A S)$ codons 12 and 13 and $B R A F$ codon 600 using a SNaPshot assay as previously described (41). The sensitivity of the SNaPshot assay that we developed was previously evaluated using plasmid dilutions and ranged between $1-5 \%$ of mutant alleles (Magnin et al, 2011; supplemental Figs. S1-S7) (41). In comparison, the Sanger assay that we used had a slightly higher level of detection that ranged between 5 and $10 \%$ of mutant alleles.

Statistical analysis. Mean values and frequencies were used for the description of continuous and categorical variables, respectively. The proportions were compared using the Chi-squared test (or Fisher's exact test, if appropriate). All statistical tests were two-sided, and P-values $<0.05$ were considered as significant.

\section{Results}

Clinicopathological characteristics. Overall, samples from 104 GISTs corresponding to 103 patients including 60 males and 43 females were available for the present study. The main clinical and pathological characteristics of the GISTs are shown in Fig. 1. The mean age at the time of diagnosis was 66.2 years ranging from 29 to 92 years. Primary tumors were localized within the stomach $(66 \%)$, small bowel $(29 \%)$, colon
A

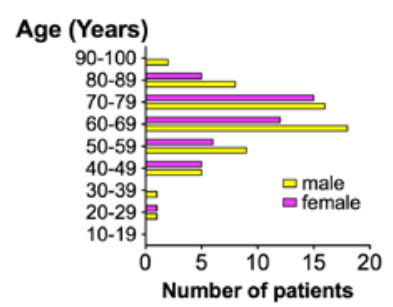

C

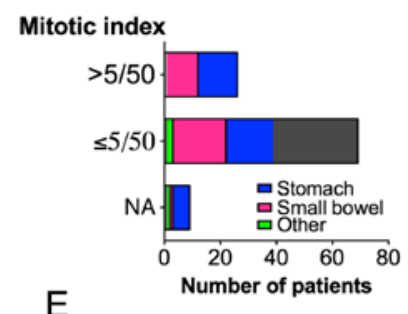

E
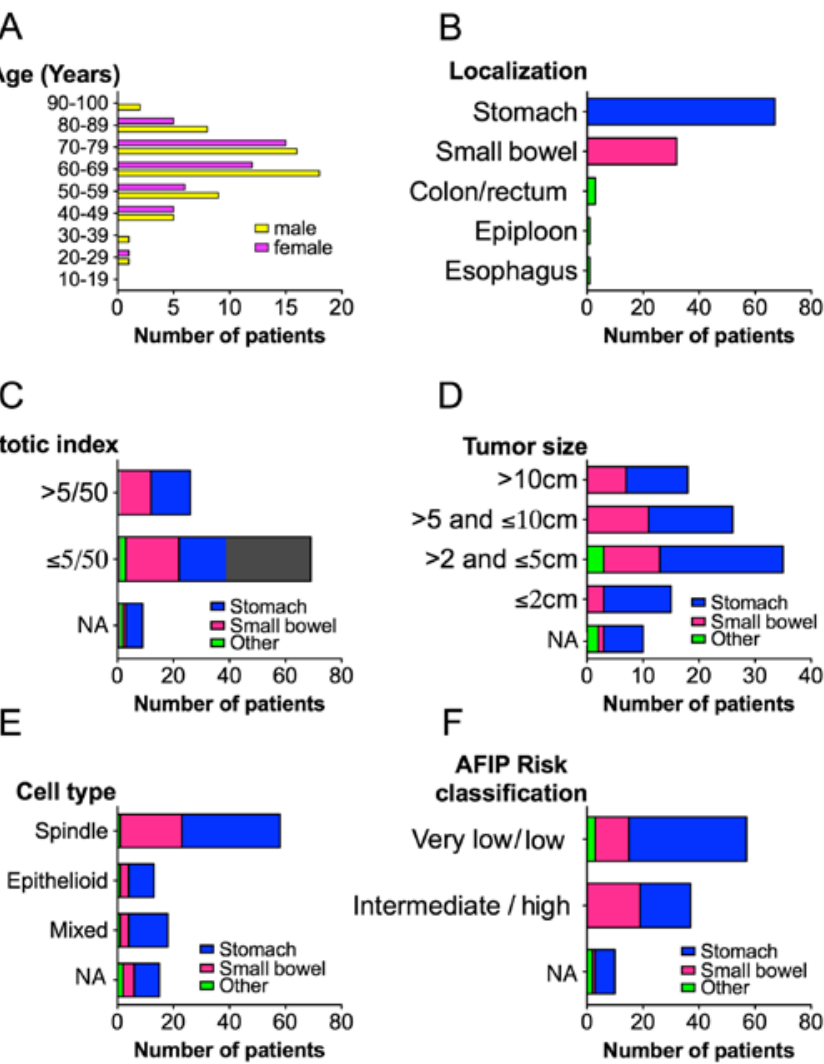

D

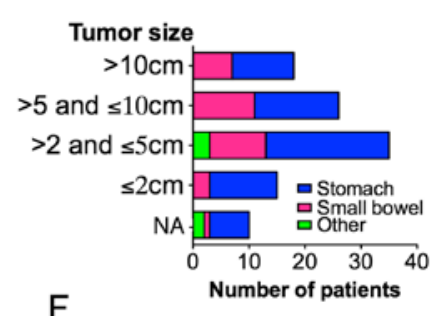

classification

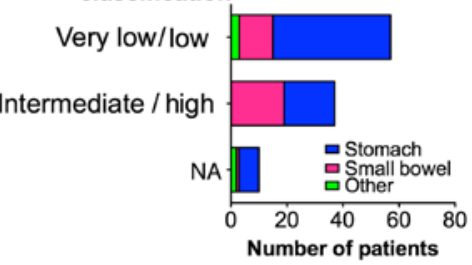

Figure 1. Clinicopathological characteristics of gastrointestinal stromal tumors (GISTs) in our series. (A and B) Distribution of patients according to their age, gender as well as GIST localization. Other diagrams represent the distribution of patients with GISTs according to: (C) the mitotic index, (D) the tumor size, (E) the cell type and (F) the Armed Forces Institute of Pathology (AFIP) risk classification and for each category, the correlation with anatomical localization of the tumors. NA, not available.

$(2 \%)$, rectum $(<1 \%)$, esophagus $(<1 \%)$ and epiploon $(<1 \%)$. A majority of GISTs $(65 \%)$ had a tumor size between 2 and $10 \mathrm{~cm}$ and the mitotic index was $<5 / 50 \mathrm{~mm}^{2}$ in the majority of cases 
Table II. Novel KIT exon 11 mutations observed in our series of GISTs.

\begin{tabular}{l} 
Mutations \\
\hline c.1649_1675del; p.Lys550_Lys558delinsIle \\
c.1668_1692delinsA ; p.Trp557_Asn564del \\
c.1670_1720del ; p.Trp557_Thr574delinsSer \\
c.1676_1681del ; p.Val560_Glu561del \\
c.1676_1696del ; p.Val560_Asn566delinsAsp \\
c.1703_1726del ; p.Tyr568_Leu576delinsPhe \\
c.1708_1719dup ; p.Tyr570_Thr574dup \\
c.1709_1735dup ; p.Ile571_Asp579dup \\
c.1717_1737dupinsCCA; p.Asp572_Asp579dupinsPro \\
c.1718_1771dup ; p.Thr574_Phe590dupinsSer \\
c.1723_1758dup ; p.Gln575_Asn586dup \\
c.1726_1738delinsG ; p.Leu576_Asp579del \\
c.1711_1758dup ; p.Asp572_Asn586dup
\end{tabular}

GISTs, gastrointestinal stromal tumors.

(65\%). Morphologically, spindle cell type represented 56\%, epithelioid $12.5 \%$ and mixed cell type $17.5 \%$ of the GISTs. At the time of diagnosis, $11 \%$ of the GISTs had synchronous metastasis. Thirty-six percent of localized GISTs were intermediate to high risk according to AFIP classification.

Mutational analysis. Characterization of the mutational status for KIT and PDGFRA was performed in all GISTs. KIT and PDGFRA mutations were detected in $90.4 \%$ cases, $71.2 \%$ in $K I T$ and $19.2 \%$ in PDGFRA while no mutation was found in $9.6 \%$ specimens. A total of 43 different mutations were detected. Among them 36 were localized in KIT exon 11 of which 13 were not referenced in the COSMIC database (Table II).

Altogether mutations in exon 9 and 11 of KIT and exon 18 of PDGFRA accounted for $93 \%$ of all mutations. Overall, the 9 most frequent mutations represented $55.2 \%$ of all mutations (Table III).

In $K I T$ exon 9, the classical duplication (p.Ala502_ Tyr503dup) was the only mutation identified.

As expected, KIT exon 11 mutations were more heterogeneous. The most frequent types of KIT exon 11 mutations were substitutions in $44.4 \%$ cases followed by deletions in $33.3 \%$ cases, complex mutations including insertions in $14.3 \%$ cases and tandem duplications in $7.9 \%$ cases. The detailed frequency of codon alterations is shown in Fig. 2. KIT exon 11 deletions were predominantly clustered in the 5 '-end of exon 11 . The most frequently mutated codons of KIT exon 11 were 557 (in $39.6 \%$ of $K I T$ exon 11 mutants), 558 and 560 (25.4\% both). The most common deletion p.Trp557_Lys558del was found in 5 cases ( $8 \%$ of $K I T$ exon 11 mutants). By contrast, all tandem duplications $(n=5)$ occurred in the 3 '-end of exon 11 . The length of the duplications varied from 3 to $51 \mathrm{bp}$, mostly involving codons 573-579.

No mutation was found in KIT exon 17 and only one mutation was found in KIT exon 13 (p.Lys642Glu).

Regarding PDGFRA, all mutations observed in exon 18 corresponded to the classical p.Asp842Val, except for 2 dele-
Table III. The 9 most frequent KIT and PDGFRA mutations in our series of GISTs.

\begin{tabular}{lc}
\hline Mutations & Percentage \\
\hline 1. PDGFRA ex 18 p.Asp842Val & 13.95 \\
2. KIT ex 9 p.Ala502_Tyr503dup & 9.60 \\
3. KIT ex 11 p.Val560Asp & 7.69 \\
4. KIT ex 11 p.Trp557Arg & 5.76 \\
5. KIT ex 11 p.Leu576Pro & 4.80 \\
6. KIT ex 11 p.Trp557_Lys558del & 4.80 \\
7. KIT ex 11 p.Val559Asp & 2.88 \\
8. KIT ex 11 p.Trp557Gly & 2.88 \\
9. PDGFRA ex 18 p.Ile843_Asp846del & 2.88 \\
\hline
\end{tabular}

PDGFRA, platelet-derived growth factor receptor $\alpha$; GISTs, gastrointestinal stromal tumors.

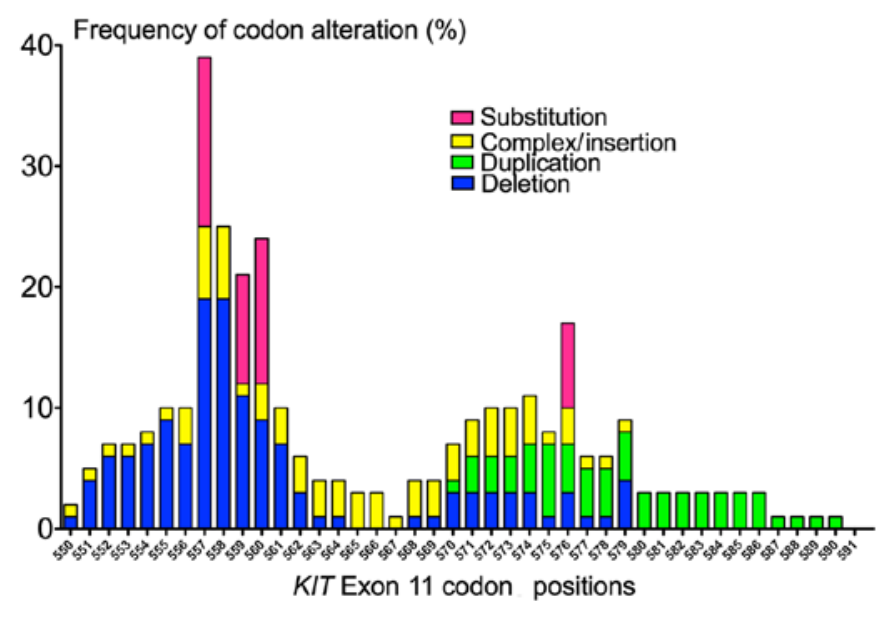

Figure 2. KIT exon 11 mutations in our series of gastrointestinal stromal tumors. The stacked charts represent the frequency of codon deletions, duplications, substitutions or complex mutations at each codon position in KIT exon 11.

tions (p.Asp842_His845del and p.Ile843_Asp846del). Only one mutation was found in exon 12 (p.Val561Asp). Of note, a patient was diagnosed with double synchronous primary GISTs localized in the stomach. Both tumors had the same histological characteristics but, interestingly, they harbored 2 different mutations in PDGFRA (p.Asp842Val and p.Val561Asp).

Distribution of patients in our series according to the mutated exon was compared with that of patients from different geographical origins included in population-based studies and clinical trials (Fig. 3) (4,21,37,38,42-52). It appeared that the distribution of mutations greatly varied according to the population studied. In comparison with other studies, more PDGFRA exon 18 mutations and less KIT/ $P D G F R A$ wild-type GISTs were found in the present study. For $K I T$ exons 9,11, 13 and 17 and for PDGFRA exon 12, our results were however in the same range.

In addition, all $K I T / P D G F R A$ wild-type tumors $(\mathrm{n}=10)$ were tested for the presence of $B R A F$ codon 600 and KRAS codon 12 and 13 mutations. No mutation was detected. Of note, one patient with wild-type GIST has been diagnosed with type I neurofibromatosis. 


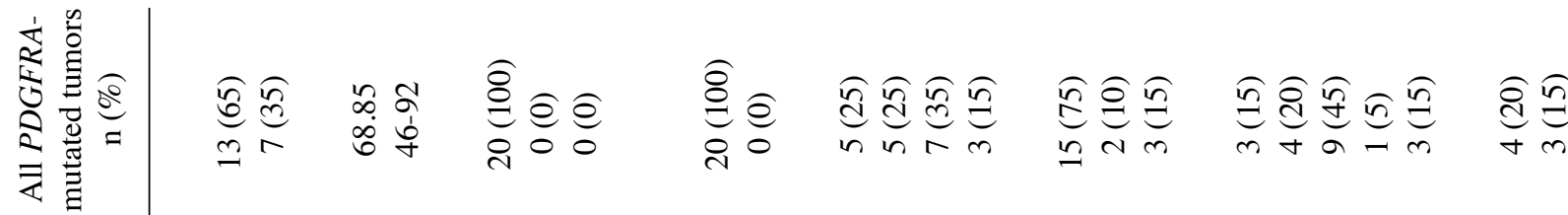

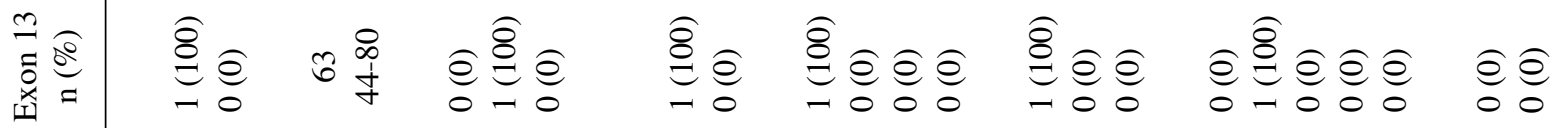

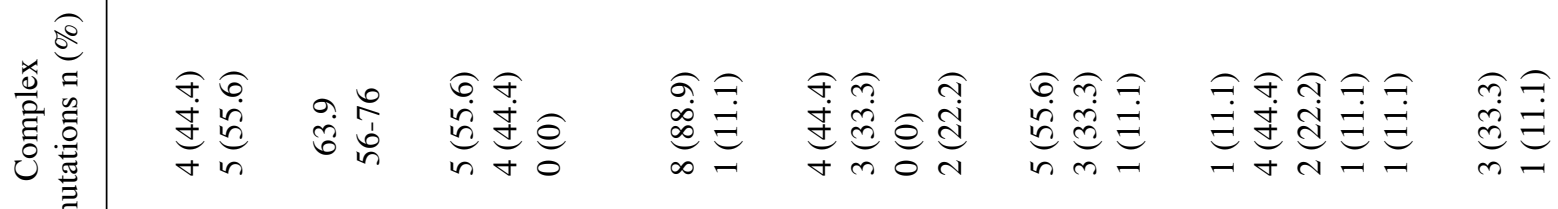

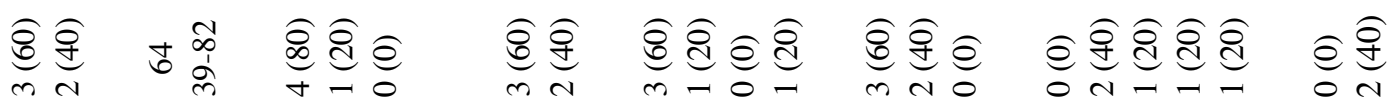

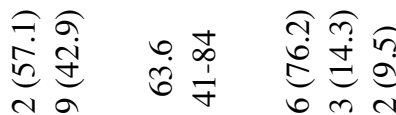

$=\frac{\mathfrak{o}}{a}$

\section{कิ}

象

$\begin{array}{ll}\infty \\ 0 \\ 0 & \infty\end{array}$

\section{0}

त

กิก

文

\&્o

$\because 0^{\infty} \infty$

$\infty$
0
$\infty$
0
0
0
0

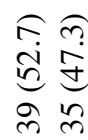

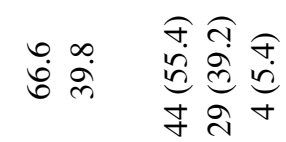

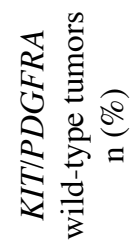

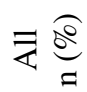

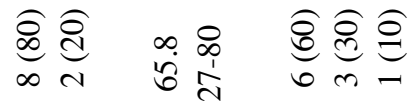

\&

ํํำ

กิ

बิ?

의

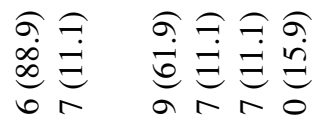

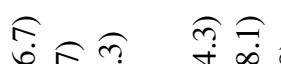

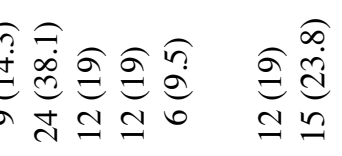

용

in

mेro

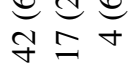

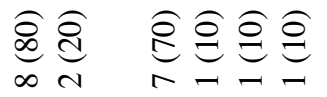

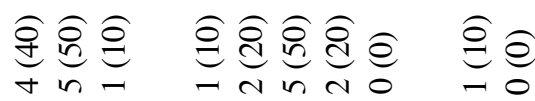

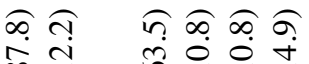

조

$\sqrt{6} \sigma$

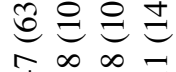

बิ่

กิก $\widehat{\sigma}=$ ติ?

宅 n 这窟

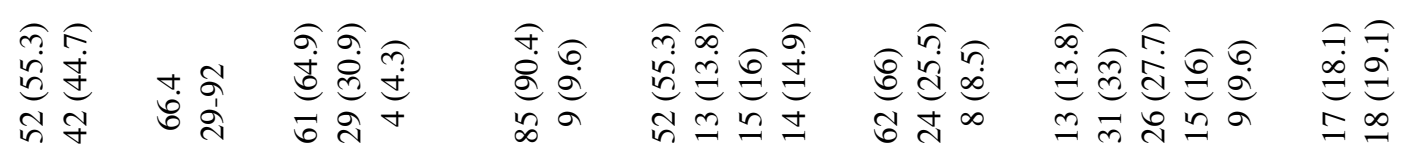

กิ

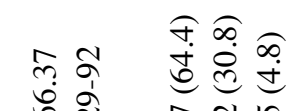

ક.

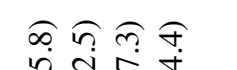

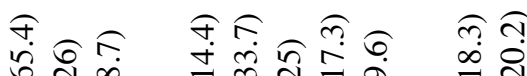

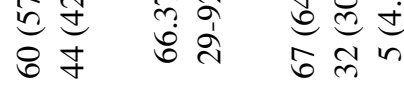

$n=\quad \infty m \infty n$

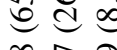

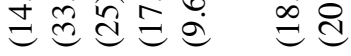

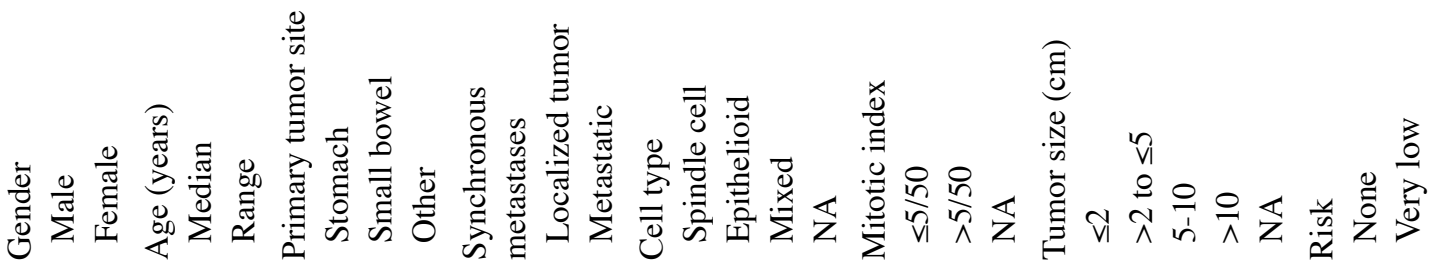


Association of tumor genotype with clinicopathological characteristics. Detailed distribution of patients according to mutations and clinicopathological characteristics is shown in Table IV.

It can be noted that GISTs with PDGFRA exon 18 mutations $(\mathrm{n}=18)$ were associated with primary gastric localization (18/18), tumors with KIT exon 9 mutations $(\mathrm{n}=10)$ were exclusively localized in the small bowel (10/10) while tumors with $K I T$ exon 11 were respectively localized in the stomach (41/63), small bowel (18/63) and other sites (4/63) $(\mathrm{p}<0.001)$.

No other significant association was observed between $K I T$ and PDGFRA mutations and the clinicopathological features of the GISTs. Furthermore, spindle cell type and mitotic index $>5 / 50 \mathrm{~mm}^{2}$ was less frequent in tumors harboring PDGFRA exon 18 mutation than in the whole series. Despite a tumor size greater than other GISTs, the estimated risk of relapse was more frequently very low/low in this subset of tumors (Table IV).

Advanced GISTs were diagnosed in 11 cases in our series and no association with a specific mutation was found. Finally, 15 patients (14\%) also presented another malignancy of which 13 were synchronous. Of note, $25 \%$ of patients with PDGFRA mutations had other malignancies.

Molecular pattern of KIT exon 11 substitutions. Single substitutions in KIT exon 11 occurred, in decreased frequency, at codons $557(\mathrm{n}=9$; p.Trp557Gly, p.Trp557Arg), $560(\mathrm{n}=8$; p.Val560Asp), 559 (n=6; p.Val559Gly, p.Val559Asp) and 576 (n=5; p.Leu576Pro). Strikingly, all KIT exon 11 substitutions $(n=28)$ shared the same $\mathrm{T}>\mathrm{N}$ molecular pattern. These substitutions occurred at nucleotides 1669, 1676, 1679 and 1727. Half of these point mutations involved T $>A$ transversion, $8 \mathrm{~T}>\mathrm{C}$ transition and $6 \mathrm{~T}>\mathrm{G}$ transversion (Table $\mathrm{V}$ and Fig. 4). No significant association was found between KIT exon 11 substitution and clinicopathological characteristics. However, patients with such mutation tended to be older than other patients of the present series (median age 69.5 vs. 66.37 in the whole cohort). Of note, in comparison with all patients, no epithelioid tumor was observed in patients with KIT exon 11 substitution, mitotic index was $\leq 5 / 50 \mathrm{~mm}^{2}$ in $86 \mathrm{vs.} 65 \%$ and tumor size was $\leq 5 \mathrm{~cm}$ in $66 \%$ in this subset of patients vs. $54 \%$ in all cases (Table IV).

\section{Discussion}

Here, we provide a prospective study of clinicopathological and molecular characteristics of 104 GISTs from a Northeastern French population.

All patients with GISTs diagnosed between August 2005 and October 2014 at the University Hospital of Besançon benefited from a routine molecular diagnosis as recommended by the French National Cancer Institute (INCa). Thus, our study reflects the distribution of clinicopathological and molecular features of GISTs in real life with the accuracy and the management of quality from a clinical laboratory.

The detailed molecular characterization of GISTs has become of great prognosis and therapeutic value in the past few years.

Indeed, treatment with the tyrosine kinase inhibitor imatinib led to significant improvement of survival of patients with KIT and PDGFRA mutated GISTs. Imatinib has been approved 


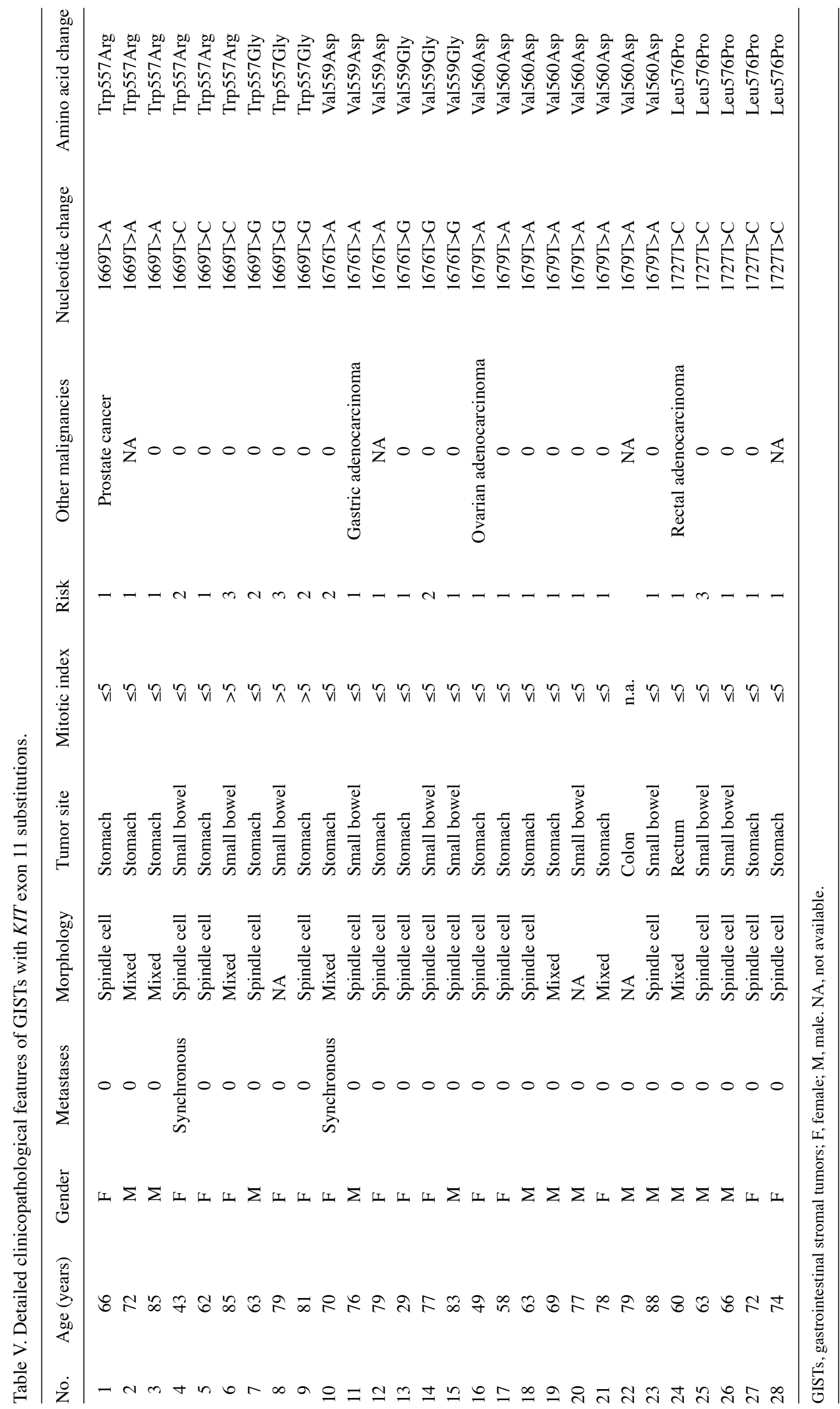




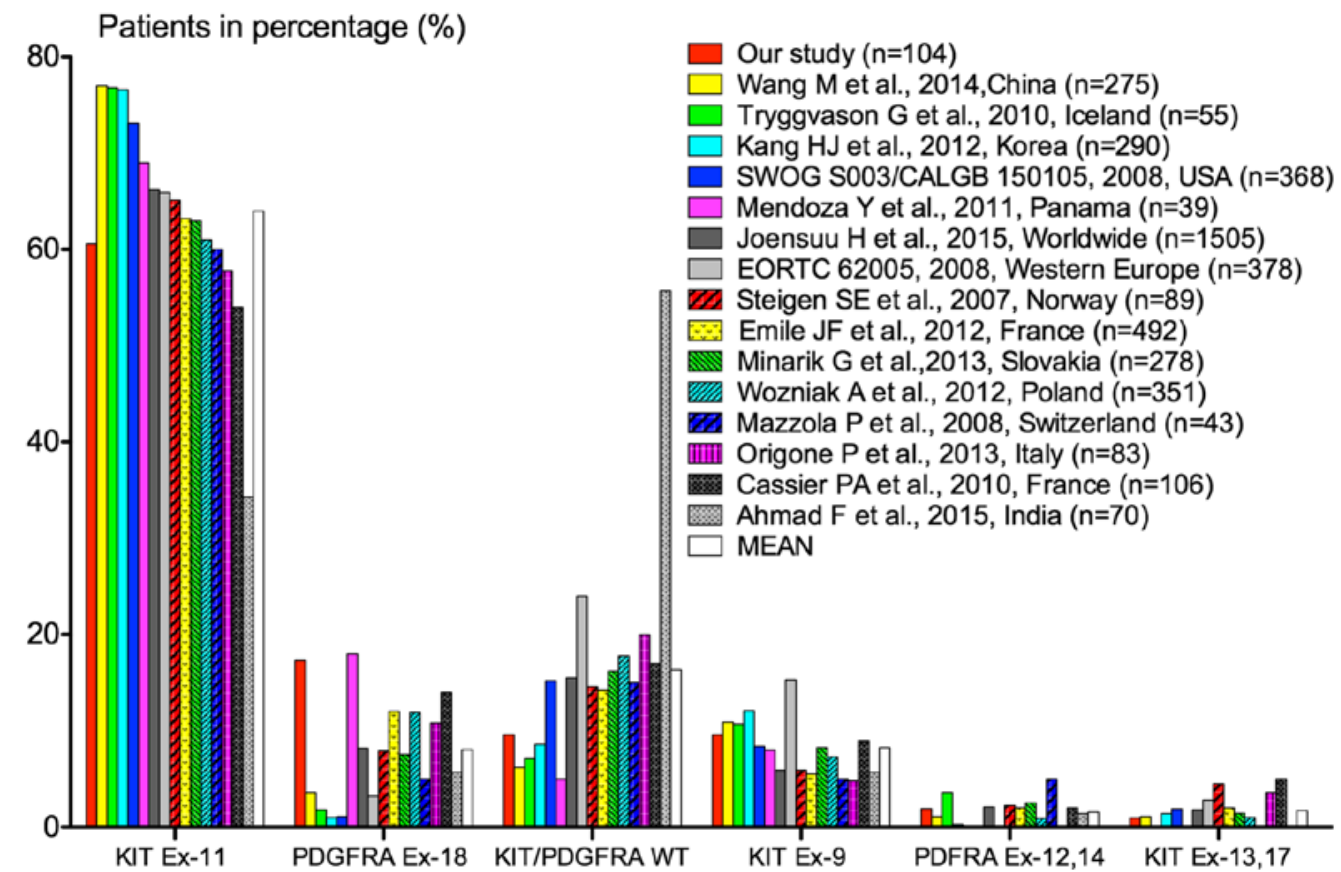

Figure 3. KIT and platelet-derived growth factor receptor $\alpha$ (PDGFRA) mutations in different series of gastrointestinal stromal tumors (GISTs). The distribution of patients with GISTs according to KIT and PDGFRA mutational status in 16 series from different regions of the globe, is represented.

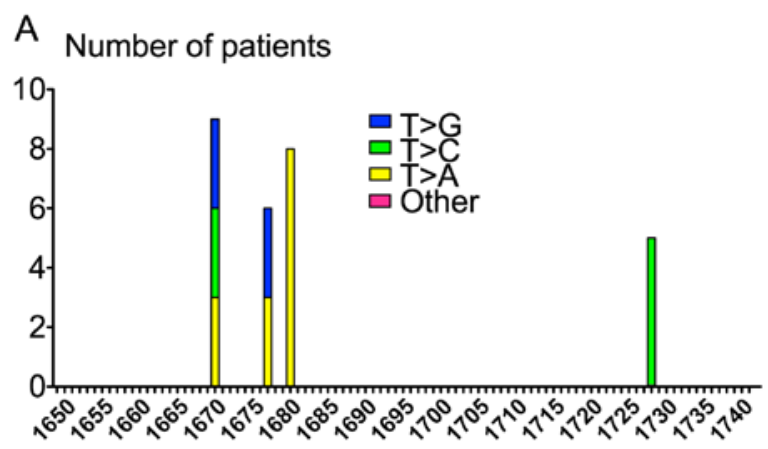

B Number of patients

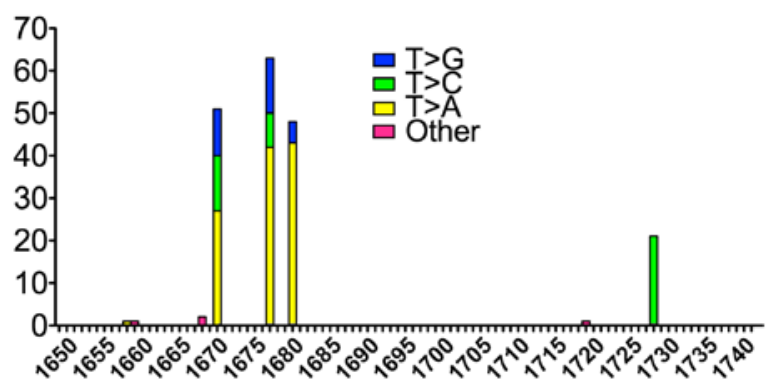

Figure 4. Nucleotide changes in KIT exon 11 substitutions. The different charts represent the distribution of patients with KIT exon 11 substitutions according to the nucleotide position and base change in (A) our series as well as in (B) the MolecGIST series.

as the first line treatment of patients with advanced GISTs and substantially increased survival of these patients $(10-20$ vs. 51-57 months median survival) (53-55). Subsequently, it has been shown that the position of KIT or PDGFRA mutations influences the response to imatinib. Thus, GISTs with KIT exon 11 mutant genotype are imatinib-responsive whereas mutations in PDGFRA exon 18 (mostly Asp842Val) are associated with resistance to imatinib. GISTs with a mutation in KIT exon 9 (mostly Ala-Tyr502-503 duplications) are imatinib-responsive but doubling the dose of imatinib $(400 \mathrm{mg}$ twice daily) increases the progression-free survival significantly (56). Treatment of KIT/PDGFRA wild-type tumors is not currently standardized and the administration of imatinib in these patients remains controversial.

Additionally, tumor genotype has been shown to have an independent prognostic relevance in patients with GISTs. KIT exon 9 duplications and KIT exon 11 deletions are known to be associated with aggressive tumor behavior and poor prognosis whereas patients with PDGFRA Asp842Val mutant GISTs usually have a favorable outcome $(57,58)$. Recently, Joensuu et al have shown that patients with PDGFRA mutations and those with KIT exon 11 duplication or deletion of one codon have favorable relapse-free survival (RFS) with surgery alone (47). Thus, KIT and PDGFRA mutation analysis provides important information to estimate the risk of recurrence in patients with localized GISTs and deserve to be investigated to select candidates for adjuvant therapy.

The distribution of somatic mutations in GISTs has previously been characterized in large population-based studies and varies widely from one region of the globe to another but the reasons for these variations still remain unknown.

Thus, KIT and PDGFRA mutations are found respectively in 70 and $10 \%$ of cases in the USA (59), 70.7 and $20 \%$ in France (4), 67.9 and $1 \%$ in China (60), and 72.4 and $6.5 \%$ in South Africa (61). Notably, the variation of the genotype mainly involves the proportion of PDGFRA-mutated tumors. Such variations may be explained by several factors. First, it may be the result of variable diagnosis delays. PDGFRA-mutated tumors are known to evolve more slowly than KIT-mutated tumors. Consequently, the series that comprised a higher 
proportion of advanced GISTs had less PDGFRA-mutated tumors. Secondly, the technical procedures used to assess the mutational status of GISTs can influence the proportion of mutations in these different series. The Sanger sequencing probably allows a more extensive detection of rare variants compared with targeted methods. Thus, it may be assumed that the implementation of next-generation sequencing in clinical laboratories will change the current molecular epidemiology of GISTs. Finally, PDGFRA mutations may vary with the ethnic origins of patients with GISTs as shown in nonsmall cell lung cancer in which a higher proportion of somatic epidermal growth factor receptor $(E G F R)$ mutations has been observed in the Asian population. In our series the distribution of KIT and PDGFRA mutations was quite similar to those of the MolecGIST study that reviewed tumor samples from 596 patients from all over France during a 24-month period. Notably, we observed a higher proportion of KIT exon 11 substitutions in the present study compared with MolecGIST (44.4 vs. $34.1 \%$ ). A focused analysis of these substitutions has displayed a common molecular pattern consisting in all cases of a $\mathrm{T}>\mathrm{N}$ point mutation located at codons 557, 559, 560 and 576. Analysis of the molecular pattern of KIT exon 11 substitutions in the MolecGIST cohort showed the same distribution with $97.9 \%$ mutations affecting a thymine at 4 different loci. Surprisingly, a recent Indian study of 70 GISTs revealed a different distribution with only $40 \%$ thymine substitutions among all KIT exon 11 point mutations (49). Thus, we suggest that environment and/or genetic background may affect the distribution of point mutations in GISTs.

Environmental risks of cancer usually include exposure to carcinogens. Characteristic mutations in KIT exon 11 in GISTs may be mutational signatures that are linked to specific mutagens. Despite an increasing number of studies, little is known about the natural history of GISTs. Notably, the role of non-genetic risk factors, such as exposure to carcinogens, is not currently known.

Genetics risks include constitutional genomic instability and DNA repair defects. Such alterations have already been suggested to play a role in the oncogenesis of GISTs. Thus, methylation of mutL homolog 1 and $M G M T$ have been observed in 60 and $49 \%$ of GISTs respectively and singlenucleotide polymorphisms (SNPs) in two other DNA repair genes, $R A D 23 B$ and $E R C C 2$, were associated with $K I T$ exon 11 mutations $(59,62)$.

Despite the advent of targeted therapies, the prognosis of GISTs, especially in advanced stages, is still poor and a better comprehension of genetic and environmental risk factors may allow the development of preventive and/or screening strategies for GISTs.

In conclusion, this study confirms existing data and enriches the knowledge of the genotypes of GISTs which is essential for therapeutic innovation. By describing 13 novel mutations in KIT, our data contribute to widen the spectrum of known mutations in GISTs and to confirm the most frequently altered regions underlying GIST development. It also confirms that $K R A S$ exon 2 and $B R A F \mathrm{~V} 600$ mutations are very scarce since no mutation was found in the wild-type GISTs in our series.

Finally, this study highlights the importance of taking into consideration the genetic and environmental risk factors favoring GIST development since the current scientific knowledge on this topic is still poor.

\section{Acknowledgements}

We would like to thank Alice Brunier, Evelyne Chezy, Laurence Madoz and Lise Rognon for the achievement of the technical procedures used in this study. We also acknowledge the Institut National du Cancer (INCa) for the financial support of the molecular diagnosis of GISTs in France. Finally, we thank the pathologists who participated in this study: Séverine Valmary Degano, Isabelle Bedgedjian, Franck Vitte, Yannick Jeffredo and Alain Petitjean.

\section{References}

1. Corless CL, Barnett CM and Heinrich MC: Gastrointestinal stromal tumours: Origin and molecular oncology. Nat Rev Cancer 11: 865-878, 2011

2. Joensuu H, Hohenberger P and Corless CL: Gastrointestinal stromal tumour. Lancet 382: 973-983, 2013

3. Monges G, Bisot-Locard S, Blay JY, Bouvier AM, Urbieta M, Coindre JM and Scoazec JY: The estimated incidence of gastrointestinal stromal tumors in France. Results of PROGIST study conducted among pathologists. Bull Cancer 97: E16-E22, 2010.

4. Emile JF, Brahimi S, Coindre JM, Bringuier PP, Monges G, Samb P, Doucet L, Hostein I, Landi B, Buisine MP, et al: Frequencies of KIT and PDGFRA mutations in the MolecGIST prospective population-based study differ from those of advanced GISTs. Med Oncol 29: 1765-1772, 2012.

5. Sarlomo-Rikala M, Kovatich AJ, Barusevicius A and Miettinen M: CD117: A sensitive marker for gastrointestinal stromal tumors that is more specific than CD34. Mod Pathol 11: 728-734, 1998

6. Hirota S, Isozaki K, Moriyama Y, Hashimoto K, Nishida T, Ishiguro S, Kawano K, Hanada M, Kurata A, Takeda M, et al: Gain-of-function mutations of c-kit in human gastrointestinal stromal tumors. Science 279: 577-580, 1998.

7. Heinrich MC, Corless CL, Duensing A, McGreevey L, Chen CJ, Joseph N, Singer S, Griffith DJ, Haley A, Town A, et al: PDGFRA activating mutations in gastrointestinal stromal tumors. Science 299: 708-710, 2003.

8. Hirota S, Ohashi A, Nishida T, Isozaki K, Kinoshita K, Shinomura Y and Kitamura Y: Gain-of-function mutations of platelet-derived growth factor receptor $\alpha$ gene in gastrointestinal stromal tumors. Gastroenterology 125: 660-667, 2003.

9. Nannini M, Biasco G, Astolfi A and Pantaleo MA: An overview on molecular biology of KIT/PDGFRA wild type (WT) gastrointestinal stromal tumours (GIST). J Med Genet 50: 653-661, 2013.

10. Agaimy A, Terracciano LM, Dirnhofer S, Tornillo L, Foerster A, Hartmann A and Bihl MP: V600E $B R A F$ mutations are alternative early molecular events in a subset of KIT/PDGFRA wild-type gastrointestinal stromal tumours. J Clin Pathol 62: 613-616, 2009.

11. Agaram NP, Wong GC, Guo T, Maki RG, Singer S, Dematteo RP, Besmer P and Antonescu CR: Novel V600E BRAF mutations in imatinib-naive and imatinib-resistant gastrointestinal stromal tumors. Genes Chromosomes Cancer 47: 853-859, 2008.

12. Hostein I, Faur N, Primois C, Boury F, Denard J, Emile JF, Bringuier PP, Scoazec JY and Coindre JM: BRAF mutation status in gastrointestinal stromal tumors. Am J Clin Pathol 133: 141-148, 2010.

13. Miettinen M, Killian JK, Wang Z-F, Lasota J, Lau C, Jones L, WalkerR,Pineda M,Zhu YJ,Kim SY, et al: Immunohistochemical loss of succinate dehydrogenase subunit A (SDHA) in gastrointestinal stromal tumors (GISTs) signals SDHA germline mutation. Am J Surg Pathol 37: 234-240, 2013.

14. Jones DH, Caracciolo JT, Hodul PJ, Strosberg JR, Coppola D and Bui MM: Familial gastrointestinal stromal tumor syndrome: Report of 2 cases with KIT exon 11 mutation. Cancer Control 22: 102-108, 2015.

15. Janeway KA, Kim SY, Lodish M, Nosé V, Rustin P, Gaal J, Dahia PL, Liegl B, Ball ER, Raygada M, et al; NIH Pediatric and Wild-Type GIST Clinic: Defects in succinate dehydrogenase in gastrointestinal stromal tumors lacking KIT and PDGFRA mutations. Proc Natl Acad Sci USA 108: 314-318, 2011. 
16. Pantaleo MA, Astolfi A, Urbini M, Nannini M, Paterini P, Indio V, Saponara M, Formica S, Ceccarelli C, Casadio R, et al; GIST Study Group: Analysis of all subunits, SDHA, SDHB, SDHC, SDHD, of the succinate dehydrogenase complex in KIT/PDGFRA wild-type GIST. Eur J Hum Genet 22: 32-39, 2014.

17. Joensuu H, Vehtari A, Riihimäki J, Nishida T, Steigen SE, Brabec P, Plank L, Nilsson B, Cirilli C, Braconi C, et al: Risk of recurrence of gastrointestinal stromal tumour after surgery: An analysis of pooled population-based cohorts. Lancet Oncol 13 265-274, 2012

18. Bischof DA, Kim Y, Dodson R, Jimenez MC, Behman R, Cocieru A, Fisher SB, Groeschl RT, Squires MH III, Maithel SK, et al: Conditional disease-free survival after surgical resection of gastrointestinal stromal tumors: A multi-institutional analysis of 502 patients. JAMA Surg 150: 299-306, 2015.

19. Fletcher CDM, Berman JJ, Corless C, Gorstein F, Lasota J, Longley BJ, Miettinen M, O'Leary TJ, Remotti H, Rubin BP, et al: Diagnosis of gastrointestinal stromal tumors: A consensus approach. Hum Pathol 33: 459-465, 2002.

20. Miettinen $M$ and Lasota J: Gastrointestinal stromal tumors: Pathology and prognosis at different sites. Semin Diagn Pathol 23: 70-83, 2006

21. Wozniak A, Rutkowski P, Piskorz A, Ciwoniuk M, Osuch C, Bylina E, Sygut J, Chosia M, Rys J, Urbanczyk K, et al; Polish Clinical GIST Registry: Prognostic value of KIT/PDGFRA mutations in gastrointestinal stromal tumours (GIST): Polish Clinical GIST Registry experience. Ann Oncol 23: 353-360, 2012.

22. Mol CD, Dougan DR, Schneider TR, Skene RJ, Kraus ML, Scheibe DN, Snell GP, Zou H, Sang BC and Wilson KP: Structural basis for the autoinhibition and STI-571 inhibition of c-Kit tyrosine kinase. J Biol Chem 279: 31655-31663, 2004.

23. Tuveson DA, Willis NA, Jacks T, Griffin JD, Singer S, Fletcher CD, Fletcher JA and Demetri GD: STI571 inactivation of the gastrointestinal stromal tumor c-KIT oncoprotein: Biological and clinical implications. Oncogene 20: 5054-5058, 2001.

24. Heinrich MC, Griffith DJ, Druker BJ, Wait CL, Ott KA and Zigler AJ: Inhibition of c-kit receptor tyrosine kinase activity by STI 571, a selective tyrosine kinase inhibitor. Blood 96: 925-932, 2000.

25. Demetri GD, von Mehren M, Blanke CD, Van den Abbeele AD, Eisenberg B, Roberts PJ, Heinrich MC, Tuveson DA, Singer S, Janicek M, et al: Efficacy and safety of imatinib mesylate in advanced gastrointestinal stromal tumors. N Engl J Med 347: $472-480,2002$

26. Heinrich MC, Corless CL, Demetri GD, Blanke CD, von Mehren M, Joensuu H, McGreevey LS, Chen CJ, Van den Abbeele AD, Druker BJ, et al: Kinase mutations and imatinib response in patients with metastatic gastrointestinal stromal tumor. J Clin Oncol 21: 4342-4349, 2003.

27. Heinrich MC, Maki RG, Corless CL, Antonescu CR, Harlow A, Griffith D, Town A, McKinley A, Ou WB, Fletcher JA, et al: Primary and secondary kinase genotypes correlate with the biological and clinical activity of sunitinib in imatinib-resistant gastrointestinal stromal tumor. J Clin Oncol 26: 5352-5359, 2008.

28. Chen LL, Trent JC, Wu EF, Fuller GN, Ramdas L, Zhang W, Raymond AK, Prieto VG, Oyedeji CO, Hunt KK, et al: A missense mutation in KIT kinase domain 1 correlates with imatinib resistance in gastrointestinal stromal tumors. Cancer Res 64: 5913-5919, 2004

29. Heinrich MC, Corless CL, Blanke CD, Demetri GD, Joensuu H, Roberts PJ, Eisenberg BL, von Mehren M, Fletcher CD, Sandau K, et al: Molecular correlates of imatinib resistance in gastrointestinal stromal tumors. J Clin Oncol 24: 4764-4774, 2006.

30. Wardelmann E, Thomas N, Merkelbach-Bruse S, Pauls K, Speidel N, Büttner R, Bihl H, Leutner CC, Heinicke T and Hohenberger P: Acquired resistance to imatinib in gastrointestinal stromal tumours caused by multiple KIT mutations. Lancet Oncol 6: 249-251, 2005.

31. Liegl B, Kepten I, Le C, Zhu M, Demetri GD, Heinrich MC Fletcher CD, Corless CL and Fletcher JA: Heterogeneity of kinase inhibitor resistance mechanisms in GIST. J Pathol 216: 64-74, 2008.

32. Nishida T, Kanda T, Nishitani A, Takahashi T, Nakajima K, Ishikawa $\mathrm{T}$ and Hirota $\mathrm{S}$ : Secondary mutations in the kinase domain of the KIT gene are predominant in imatinib-resistant gastrointestinal stromal tumor. Cancer Sci 99: 799-804, 2008.
33. Demetri GD, van Oosterom AT, Garrett CR, Blackstein ME, Shah MH, Verweij J, McArthur G, Judson IR, Heinrich MC, Morgan JA, et al: Efficacy and safety of sunitinib in patients with advanced gastrointestinal stromal tumour after failure of imatinib: A randomised controlled trial. Lancet 368: 1329-1338, 2006.

34. George S, Wang Q, Heinrich MC, Corless CL, Zhu M, Butrynski JE, Morgan JA, Wagner AJ, Choy E, Tap WD, et al: Efficacy and safety of regorafenib in patients with metastatic and/or unresectable GI stromal tumor after failure of imatinib and sunitinib: A multicenter phase II trial. J Clin Oncol 30: 2401-2407, 2012

35. Guo T, Agaram NP, Wong GC, Hom G, D'Adamo D, Maki RG, Schwartz GK, Veach D, Clarkson BD, Singer S, et al: Sorafenib inhibits the imatinib-resistant $K I T^{T 670 I}$ gatekeeper mutation in gastrointestinal stromal tumor. Clin Cancer Res 13: 4874-4881, 2007.

36. Cullinane C, Natoli A, Hui Y, Conus N, Jackson S, Brüggen J, Manley PW and McArthur GA: Preclinical evaluation of nilotinib efficacy in an imatinib-resistant KIT-driven tumor model. Mol Cancer Ther 9: 1461-1468, 2010.

37. Steigen SE, Eide TJ, Wasag B, Lasota $J$ and Miettinen M: Mutations in gastrointestinal stromal tumors - a population-based study from Northern Norway. APMIS 115: 289-298, 2007.

38. Mazzola P, Spitale A, Banfi S, Mazzucchelli L, Frattini M and Bordoni A: Epidemiology and molecular biology of gastrointestinal stromal tumors (GISTs): A population-based study in the South of Switzerland, 1999-2005. Histol Histopathol 23: 1379-1386, 2008

39. Nowak F, Soria JC and Calvo F: Tumour molecular profiling for deciding therapy-the French initiative. Nat Rev Clin Oncol 9: 479-486, 2012.

40. Ye J, Coulouris G, Zaretskaya I, Cutcutache I, Rozen S and Madden TL: Primer-BLAST: A tool to design target-specific primers for polymerase chain reaction. BMC Bioinformatics 13: 134,2012

41. Magnin S, Viel E, Baraquin A, Valmary-Degano S, Kantelip B, Pretet JL, Mougin C, Bigand M, Girardo B, Borg C, et al: A multiplex $\mathrm{SNaPshot}$ assay as a rapid method for detecting $K R A S$ and $B R A F$ mutations in advanced colorectal cancers. J Mol Diagn 13: 485-492, 2011.

42. Cassier PA, Ducimetière F, Lurkin A, Ranchère-Vince D, Scoazec JY, Bringuier PP, Decouvelaere AV, Méeus P, Cellier D, Blay JY, et al: A prospective epidemiological study of new incident GISTs during two consecutive years in Rhône Alpes region: Incidence and molecular distribution of GIST in a European region. Br J Cancer 103: 165-170, 2010.

43. Mendoza Y, Singh C, Castillo Mewa J, Fonseca E, Smith R and Pascale JM: Beginning of personalized medicine in Panama: Molecular and pathological characteristics of gastrointestinal stromal tumors from archival paraffin-embedded tissue. Oncol Lett 2: 941-947, 2011.

44. Heinrich MC, Owzar K, Corless CL, Hollis D, Borden EC, Fletcher CD, Ryan CW, von Mehren M, Blanke CD, Rankin C, et al: Correlation of kinase genotype and clinical outcome in the North American Intergroup Phase III Trial of imatinib mesylate for treatment of advanced gastrointestinal stromal tumor: CALGB 150105 Study by Cancer and Leukemia Group B and Southwest Oncology Group. J Clin Oncol 26: 5360-5367, 2008.

45. Sciot R, Debiec-Rychter M, Daugaard S, Fisher C, Collin F, van Glabbeke M, Verweij J, Blay JY, Hogendoorn PCEORTC Soft Tissue and Bone Sarcoma Group, et al; Australasian Trials Group: Distribution and prognostic value of histopathologic data and immunohistochemical markers in gastrointestinal stromal tumours (GISTs): An analysis of the EORTC phase III trial of treatment of metastatic GISTs with imatinib mesylate. Eur J Cancer 44: 1855-1860, 2008.

46. Kang HJ, Ryu MH, Kim KM, Park YS, Choi J, Ryoo BY, Kim WH, Im SA, Bang YJ, Park SH, et al: Imatinib efficacy by tumor genotype in Korean patients with advanced gastrointestinal stromal tumors (GIST): The Korean GIST Study Group (KGSG) study. Acta Oncol 51: 528-536, 2012.

47. Joensuu H, Rutkowski P, Nishida T, Steigen SE, Brabec P, Plank L, Nilsson B, Braconi C, Bordoni A, Magnusson MK, et al: KIT and PDGFRA mutations and the risk of GI stromal tumor recurrence. J Clin Oncol 33: 634-642, 2015.

48. Origone P, Gargiulo S, Mastracci L, Ballestrero A, Battistuzzi L, Casella C, Comandini D, Cusano R, Dei Tos AP, Fiocca R, et al; Liguria GIST Unit: Molecular characterization of an Italian series of sporadic GISTs. Gastric Cancer 16: 596-601, 2013. 
49. Ahmad F, Lad P, Bhatia S and Das BR: Molecular spectrum of $c-K I T$ and PDGFRA gene mutations in gastro intestinal stromal tumor: Determination of frequency, distribution pattern and identification of novel mutations in Indian patients. Med Oncol 32: 424, 2015

50. Wang M, Xu J, Zhao W, Tu L, Qiu W, Wang C, Shen Y, Liu Q and Cao H: Prognostic value of mutational characteristics in gastrointestinal stromal tumors: A single-center experience in 275 cases. Med Oncol 31: 819, 2014.

51. Minárik G, Plank L, Lasabová Z, Szemes T, Burjanivová T, Szépe P, Buzalková V, Porubský D and Sufliarsky J: Spectrum of mutations in gastrointestinal stromal tumor patients - a population-based study from Slovakia. APMIS 121: 539-548, 2013.

52. Tryggvason G, Hilmarsdottir B, Gunnarsson GH, Jónsson JJ, Jónasson JG and Magnússon MK: Tyrosine kinase mutations in gastrointestinal stromal tumors in a nation-wide study in Iceland. APMIS 118: 648-656, 2010.

53. Blanke CD, Rankin C, Demetri GD, Ryan CW, von Mehren M, Benjamin RS, Raymond AK, Bramwell VH, Baker LH, Maki RG, et al: Phase III randomized, intergroup trial assessing imatinib mesylate at two dose levels in patients with unresectable or metastatic gastrointestinal stromal tumors expressing the kit receptor tyrosine kinase: S0033. J Clin Oncol 26: 626-632, 2008.

54. Blanke CD, Demetri GD, von Mehren M, Heinrich MC, Eisenberg B, Fletcher JA, Corless CL, Fletcher CD, Roberts PJ, Heinz D, et al: Long-term results from a randomized phase II trial of standard- versus higher-dose imatinib mesylate for patients with unresectable or metastatic gastrointestinal stromal tumors expressing KIT. J Clin Oncol 26: 620-625, 2008.

55. Joensuu H, Fletcher C, Dimitrijevic S, Silberman S, Roberts P and Demetri G: Management of malignant gastrointestinal stromal tumours. Lancet Oncol 3: 655-664, 2002.
56. Gastrointestinal Stromal Tumor Meta-Analysis Group (MetaGIST): Comparison of two doses of imatinib for the treatment of unresectable or metastatic gastrointestinal stromal tumors: A meta-analysis of 1,640 patients. J Clin Oncol 28: 1247-1253, 2010 57. Wardelmann E, Losen I, Hans V, Neidt I, Speidel N, Bierhoff E, Heinicke T, Pietsch T, Büttner R and Merkelbach-Bruse S: Deletion of Trp-557 and Lys-558 in the juxtamembrane domain of the $c$-kit protooncogene is associated with metastatic behavior of gastrointestinal stromal tumors. Int J Cancer 106: 887-895, 2003.

58. Andersson J, Bümming $P$, Meis-Kindblom JM, Sihto $H$, Nupponen N, Joensuu H, Odén A, Gustavsson B, Kindblom LG and Nilsson B: Gastrointestinal stromal tumors with KIT exon 11 deletions are associated with poor prognosis. Gastroenterology 130: 1573-1581, 2006.

59. O'Brien KM, Orlow I, Antonescu CR, Ballman K, McCall L, DeMatteo R and Engel LS: Gastrointestinal stromal tumors, somatic mutations and candidate genetic risk variants. PLoS One 8: e62119, 2013

60. He HY, Fang WG, Zhong HH, Li Y, Zheng J, Du J, Heng WJ and Wu BQ: Status and clinical implication of c-kit and PDGFRA mutations in 165 cases of gastrointestinal stromal tumor (GIST). Zhonghua Bing Li Xue Za Zhi 35: 262-266, 2006 (In Chinese).

61. Baker G, Babb C, Schnugh D, Nayler S, Louw M, Goedhals J, Bringuier PP, Blay JY and Willem P: Molecular characterisation of gastrointestinal stromal tumours in a South African population. Oncol Lett 5: 155-160, 2013.

62. Saito K, Sakurai S, Sano T, Sakamoto K, Asao T, Hosoya Y, Nakajima T and Kuwano H: Aberrant methylation status of known methylation-sensitive $\mathrm{CpG}$ islands in gastrointestinal stromal tumors without any correlation to the state of $c$-kit and PDGFRA gene mutations and their malignancy. Cancer Sci 99: 253-259, 2008. 